\title{
MARINE FISHERIES OF GREAT BRITAIN
}

$\mathrm{O}^{\mathrm{N}}$ N September 13 a symposium on fisheries was held by Section D (Zoology) of the British Association, under the chairmanship of Prof. $H$. Graham Cannon.

Mr. Michael Graham opened with a paper on the theory of fishing, as it had developed since T. $H$. Huxley's common-sense dictum of 1883 . This was that if natural mortality took more fish than the fishermen did, it was useless to regulate fishermen, whose efforts had no appreciable effect on the number of fish in the sea. In the meantime, history has shown that, in the demersal fish stocks near the British Isles, there is a persistent downward trend in catch per unit of effort, culminating in a chronic state of no profit in the 1930's. Marking experiments gave returns of 36 rising to 40 and 55 per cent of plaice returned within one year of marking. In order to put the facts in their places, it has been necessary to develop a theory of fishing. Now that eleven nations have signed the agreement of 1947 , by which they will take a variety of useful measures as a start, it is necessary to state the theory in the universal language of mathematics, so that all parties can assess precisely what is advocated. The theory, as developed by the Ministry of Agriculture's Fisheries Laboratory at Lowestoft, began with Huxley's dictum about natural mortality and mortality by fishing; and added the factor of growth, because it is a fall in weight rather than in numbers that hurts the fishermen. The latest form of the theory is an equation by Beverton and Holt, which enables conservative measures, such as mesh regulation and control of fishing power, to be messured against each other in terms of the steady yield that would be obtained under different conditions. Attention was directed to Huxley's attack on any regulations that were not supported by strong evidence, and it was emphasized that the onus for showing the need for regulation should always lie on those who advocate it.

It was, therefore, quite in keeping that $\mathrm{Mr}$. E. Ford should follow with a paper directing attention to the strong individualism of fishermen, as perhaps their most marked common trait. He has found the same individualism in fishery research workers, and said he suspects that it is also characteristic of fish! Mr. Ford made it clear that he regards these manifestations as important, and pleaded against their submergence in team-work. The chairman supported him in this ; the present writer had not the opportunity of pointing out that strong individualism is characteristic of the members of all good teams, as may be checked by observations in any cricket pavilion. Probably Mr. Ford and also the chairman meant to attack petty hierarchies. It was clear that, as $\mathrm{Mr}$. Ford sees it, the main problem of organisation of research, or of any other activity, is the use and encouragement of individuality, not its smoothing or repression. As it was put to 'Alice', "What does $1+1+1$... make ?" ; and Mr. Ford sees each 1 different from the others. It is respectfully suggested that the answer to this problem is the team, as properly understood.

In refreshing contrast to the preceding two papers, Mr. G. A. Steven gave a straightforward account of a piece of descriptive fishery research, namely, the elucidation of the seasonal cycle in the mackerel of the Celtic Sea. Contrary to general belief, the main spawning ground of the mackerel is in an area as big as Cornwall, lying over the edge of the continental shelf south of Ireland. Spawning takes place in summer, shifting to the eastward from April to June ; but the movement of fish successively joining it is westerly. During the winter, the mackerel is a demersal fish, lying near slopes in the depth contours, for some reason as yet unexplained. Turning to races of mackerel in other parts of the world, $\mathrm{Mr}$. Steven has found evidence of a similar behaviour pattern, correlated with depth, but naturally producing superficially different appearances where the depth contours are differently orientated. Thus, spawning in the Skagerak is crowded in to the coast, and so on. Prof. W. Garstang expressed the pleasure of the meeting at listening to Mr. Steven's vivid account of this work, and referred to his own interest in the subject more years ago than he claimed to remember. As a fishery naturalist at Plymouth, he had found that while all the European mackerel populations resemble each other closely, the North American mackerels are distinguished clearly, in samples of as few as a dozen, by having more spots in their pattern, and in other meristic characters.

Prof. J. E. G. Raymont gave an account of the now famous experiments on fertilization of Loch Sween, especially of the effects in increase of fauna of the loch bed-Chironomids, Cardium, etc. Bar the possibility of the effects being by ill-chance due to natural fluctuations-a point raised later by Dr. Cole in discussion-the results showed very clearly how fertilization with nitrate and phosphate had led to notable increases in benthos, time-lagged compared with the increases in plankton, and persisting for a year or so after fertilization had ceased. Increased growth of flounders and plaice followed, achieving values equal to the best natural areas. Prof. Raymont called for extension of the work to an inshore area of the more open sea; but in the discussion that followed, doubt was expressed whether a suitably self-contained area could be found.

For Mr. A. R. Margetts and himself, Mr. S. J. Holt read a paper on the effect of the War on the stock of plaice. Using Beverton and Holt's equation, already given by Mr. Graham, they had worked out what the density of plaice at the end of five years rest from fishing should be, on the basis of data of growth and mortality from the inter-war period. The estimate agreed fairly well with the actual density in 1945, obtained by back extrapolation from 1946, in which year the series of observations was renewed. However, not all the plaice in the North Sea enjoyed a respite from fishing. The younger fish on the eastern side of the North Sea suffered increased fishing from an augmented Danish fleet. The resulting thinning probably accounted for the increased growth-rate found in the younger fish, and it was only after the necessary allowance had been made that the theory gave precisely the same result as the actual, namely, five-fold. In order to take account of changes in growth-rate with changed density of stock, resulting from changed fishing-rates, the authors had used conclusions from Dr. Ben Dawes' experiments on growth of plaice in relation to food supply, supported by Margaret Brown's work on trout. With these they again applied the equation for the yield of a fishery, but with the plaice in the position of the fisherman, and the food of the plaice as its 'fish'. 
In the symposium as a whole, the present writer got the impression that many zoologists preferred the more robust factual papers, and regretted the necessity for mathematical theory-useful as it has been in the more delicate and abstract sciences of physies and chemistry.

Michael Graham

\section{INBREEDING AND HYBRID VIGOUR IN CROPS AND LIVESTOCK}

$\mathrm{A}$

$T$ the British Association meeting in Brighton, Sections M (Agriculture), K (Botany) and D (Zoology) held a joint discussion on September 10 to discuss "Inbreeding and Hybrid Vigour in Livestock and Crop Improvement". The chair was taken by Sir John Russell.

The symposium was opened by Dr. J. M. Rasmusson, director of the Swedish Sugar Company's Breeding Institute, at Hilleshög, Sweden, with an account of his extensive work on the improvement of Swedish sugar beet. The chief effects of inbreeding sugar beet are to inerease genetical homogeneity and to decrease productivity. At the same time, the adaptability of the plants to varying environmental conditions is lowered while the effects of environmental differences are increased : the plants are, in fact, less able to tolerate and adjust themselves to changes in extermal circumstances. The chemical constitution of the root, an important consideration in sugar beet, is scarcely affected by inbreeding.

The chief value of inbreeding is therefore to produce lines with specific and reliable features. It may also be of use in isolating lines in which troublesome associations between desirable and undesirable char. acters have been broken by changing the linkage relations of the genes. No practically useful types have been produced by continued self-pollination in Sweden; but a less-rigorous type of inbreeding, based on the use of maternal progenies between which selection is exercised, has given valuable lines. It has been observed, too, that rigorous mass selection, especially where the number of parent plants is kept small in each generation, produces the practically useful results of loose inbreeding.

When these various partially inbred lines have been raised, suitable mixtures of them can be used in bulk crosses. When this is done, nearly all the seed is from crossing though, of course, all the $\frac{n(n-1)}{2}$ crosses possible between the $n$ lines are present more or less equally in the bulk. The bulk crosses are of commercial value because of their high yields and adaptability to environmental circumstances. The more different in origin were the parent lines, the greater the improvement on crossing; and crosses between lines produced by mass selection under different conditions generally excel those between lines raised by selection between maternal progenies. The effect of crossing, like that of inbreeding, on the chemical constitution is small. Sugar percentage may be slightly reduced though not to an extent sufficient to offset the increase in root yield.

Dr. Rasmusson concluded by mentioning a special case of crossing. Tetraploids, produced by colchicine treatment, yield 5-10 per cent less sugar than the comparable diploids. But the triploids from crossing diploid and tetraploid exceed the diploids by some 5 per cent. The triploid lines cannot, of course, be maintained from seed; but bulk crossing of diploids and tetraploids yields a mixture of the three chromosome types the average productivity of which sufficiently exceeds that of the diploid to make it commercially valuable.

Prof. R. A. Fisher next dealt with the genetical theory of inbreeding, which, as he pointed out, is essentially a means of manipulating the genetic materials so as to control their strueture and composition. Inbreeding produces lines of predictable behaviour, particularly in their properties in subsequent crosses, even in respect of the numerous genes the effects of which are so small as to preclude their being followed by the mendelian method. Inbreeding is a tool the success of which has been so great in plant improvement that it can scarcely fail to achieve wide use in both plant and animal improvement in the future. Yet a theoretical understanding of its operation seems largely to be lacking, and very diverse opinions are held at present as to the reason for its success.

It is clear that the effect of inbreeding, particularly the production of an inbreeding depression which can be wiped out by one generation's crossing, must imply dominance of the genes concerned, and the genetical theory of the origin of dominance throws some light on how this could come about. The lines isolated by inbreeding differ greatly in their genetical qualities, and selection ean be exercised among them at three stages in their production, namely, in the choice of individuals with which to start the inbreeding, in the choice of individuals for continuing the lines during the inbreeding, and in the choice of lines, once established as true-breeding, for use, especially in subsequent crosses. Of these, selection among the established lines is the most valuable, because the true-breeding nature of these lines permits selection based on extensive testing of a wide variety of them. Indeed, this facility offered for increasingly accurate selection is the essential advantage conferred by inbreeding. The rapid improvement in the accuracy of variety trials, made possible by replicated and randomized field designs, has played an important part in refining the selection which has been so successfully practised in the production of hybrid maize.

Mr. G. M. L. Haskell, who followed Prof. Fisher, gave an account of the theory and practice of hybrid maize production. Hybrid maize represents so great an advance over the open-bred varieties which preceded it that it has now replaced the latter virtually completely in the corn belt of the United States. Maize is naturally a cross-pollinator, and genetically the plants are mostly heterozygous. Ordinary methods of selection had shown themselves incapable of materially improving the open-bred varieties of maize before the new methods were introduced. The introduction of the inbreeding technique has led to the production of a great variety of lines which, though all showing inbreeding depression in greater or lesser degree, are uniform and virtually truebreeding and have satisfactory plant characters. Hybridization of inbreds, which is made easy by the monœcious habit of the plants, produces offspring the hybrid vigour of which is often such that they surpass in yield not merely the inbreds themselves but also the open-bred varieties from which these inbreds were produced. Every one of the hybrid plants is a potential yielder, and the hybrid families are uniform 